\title{
Relation between the size and incidence of malignancy in solitary thyroid nodule
}

\author{
Yasser Hatata ${ }^{(1)}$; Mohamed Ibrahim ${ }^{(2)}$; Mohamed Fathi Mohamed ${ }^{(3)}$ \\ (1) professor of General Surgery, Faculty of Medicine, Fayoum University \\ (2) Assistant professor General Surgery, Faculty of Medicine, Fayoum University \\ (3) General Surgery department, fayoum general hospital
}

Corresponding author: Mohamed Fathi Mohamed

Mail:mwmm2012@yahoo.com

Tel:01004536774

\section{ABSTRACT}

Background: The thyroid nodule is a common entity, while autopsy data indicate a $50 \%$ prevalence of thyroid nodules larger than one centimeter in patients without clinical evidence of thyroid disease, the prevalence of palpable nodules is only 4 to $7 \%(1,2)$.

Thyroid nodules warrant removal when they are large enough to be symptomatic, or if there is a concern for malignancy, the majority of nodules are asymptomatic , and with only 5 to $10 \%$ of nodules being malignant, the decision to operate is made on therapeutic or diagnostic grounds $(3,4)$.

Objective: This study aims to discuss the relation between the size and the incidence of malignancy in the solitary thyroid nodule.

Methods: This is a prospective study including 25 female patients admitted to our hospital (Fayoum university hospital) for surgical treatment of solitary thyroid nodule. The study started from the 1st of August 2018 to the 1st of November 2018. The study was

\section{INTRODUCTION}

Patients most often present with a large palpable nodule in the neck or a report of an incidental nodule found on imaging studies performed for another reason(5). A single dominant or solitary nodule is more likely to represent carcinoma than a single nodule within a multi-nodular gland, with an incidence of malignancy from 2,7 to $30 \%$ and approved by the medical ethics committee of the Faculty of Medicine, Fayoum University. Results: Our study included 25 female patients who were operated for clinically detected STN, divided according to the size of the nodule into three groups with correlation between the size of the nodule and the incidence of malignancy.

The results of the studied sample showed the following:

Group A: the nodule size was less than $2 \mathrm{~cm}$ : including 2 patients (8\%). and both were benign, with incidence of malignancy zero.

Group B: the nodule size $2-4 \mathrm{~cm}$ : included 20 patients $(80 \%) .17$ patients were benign, and 3 patients were malignant, with incidence of malignancy (15\%)

Group C: the nodule size was more than $4 \mathrm{~cm}$ : included 3 patients( $12 \%)$, two patients were benign, and one was malignant, with incidence of malignancy (33\%).

Conclusion: These contradictory results show that the size of the nodule is not reliable at predicting malignancy and should not be applied for medical decision making.

from 1,4 to $10 \%$ respectively (6). Important elements in the patient's history which increase the likelihood of malignancy include prior head and neck irradiation, reports of rapid growth, dysphagia, dysphonia, male gender ,presentation at extremes of age (less than 20 years or more than 70 years) and a family history of medullary thyroid carcinoma or 
multiple endocrine neoplasia $(7,8)$. The goal of thyroid nodule evaluation is to accurately assess the risk of such nodule is cancerous via methods that are accurate precise, yet also safe, cost effective and without morbidity (9). Ultrasonography is far more sensitive than palpation, as it detects nodules of any size in up to $67 \%$ of the general population(10). Fineneedle aspiration is the primary diagnostic methodology used for thyroid evaluation, first introduced over fifty years ago, Thyroid

\section{AIM OF THE WORK}

This study aims to discuss the relation between the size and the incidence of malignancy in the

\section{PATIENT AND METHODS}

The study is prospective, controlled trial. It includes 25 patients. The patients were admitted from the outpatient department to Fayoum university hospitals, Fayoum city, Egypt, after being diagnosed with solitary thyroid nodule or dominant nodule. All patients were intended to be euthyroid and all are candidate for hemi-thyroidectomy to the affected lobe. Exploration of the contralateral lobe was done and fine nodularity was found in five patients and total thyroidectomy was done in three patients. in the period from November 2017 to November 2018. The patients were orally and officially consented using the standard form of the informed written consent form. The study was approved by the medical ethics committee of the Faculty of Medicine, Fayoum University.

\section{Inclusion criteria}

1-patients with solitary cold thyroid nodule in euthyroid gland

2-patients with dominant cold thyroid nodule in euthyroid gland

3-patients fit for general anesthesia

4-patients accepting informed consent by

liable complications

5-female patients nodule FNA has proven to be of high value because nearly $70 \%$ of aspirates return benign, these results are highly accurate and allow for conservative management, However FNA is imperfect because $20-25 \%$ of samples return indeterminate $(11,12)$. One such hypothesized variable is thyroid nodule size ,which can be measured with great accuracy and precision(5). previous studies suggested that nodule size may assist in cancer risk assessment $(13,14)$.

solitary thyroid nodule

\section{Exclusion criteria}

1-patients with diffusely enlarged thyroid gland

2-patients un-fit for general anesthesia

3-Recurrent cases

4-patients with thyrotoxicosis

5-Patients refused the consent

6-male patients

\section{Preoperative Assessment}

Each patient was assessed regarding the following

\section{History}

Personal History: Full clinical history with special attention to age, sex, residence, menstrual history, special habits of medical importance (drug abuse and/or smoking).

Complaint: of the patient which is usually neck swelling.

\section{History of present illness:}

Onset, course, duration of the swelling, and other neck swellings(LN or metastasis) .

Pain: site, character, radiation, what increase and decrease, is it localized to the swelling or radiating to the ear.

Pressure manifestations: dyspnea, dysphagia, hoarseness of voice, black outs, dizziness, ear pain. 
Toxic manifestations: nervous (insomnia, irritability, fine tremors, night mares), cardiac (palpitation, heart failure), metabolic (heat intolerance, thyroid paradox), eye manifestations (exophthalmos, diplopia), genital (menorrhagia, amenorrhea), GIT (diarrhea), urinary (polyuria), skin (sweaty, warm), muscle (myopathy), bone (osteoporosis).

\section{Hypo-thyroid manifestations: slow} thinking, apathy tendency to sleep, loss of appetite, increased body weight, oligomenorrhea, constipation, intolerance to cold.

\section{Metastatic manifestations}

Liver metastasis: jaundice, Rt. Hypo-chondrial pain

Bone metastasis: bone pain, pathological fracture.

\section{Past history:}

Common disease (DM, HTN, TB, DVT...), radiation exposure to the neck, family history of thyroid disease, past history of previous thyroid surgery and other operation.

Family history of thyroid disease

\section{Clinical Examination}

Full general examination of the patient with special attention to signs of complications as pressure manifestations, thyrotoxicosis, malignancy and retro-sternal extension. The neck was examined for any other swellings to exclude LN metastasis. The abdomen, chest, axial skeleton, and CNS were examined for clinical manifestations of distant metastasis.

\section{3- Laboratory evaluation Thyroid} profile(TSH, Free T3, Free T4), complete blood count (CBC), ALT, AST, Urea, Creatinine, serum albumin, P.T, PC, INR and blood sugar

\section{4-Radiological evaluation: Neck US} confirm diagnosis as a thyroid nodule, assess the number and the size of the nodules, the consistency, vascularity of the gland by duplex, neck LN metastasis also can be assessed by US, infiltration of the surrounding structures, and retro-sternal extension.

plain chest radiography to detect any retrosternal extension and any lung metastasis.

Radio-isotope scan is done to detect if the nodule is cold, worm, or hot
CT scan was done for cases suspecting retrosternal extension or suspecting malignancy to assess extra-thyroidal extension

FNAC: is done for all patients

ECG: to assess any cardiac complications due to thyrotoxicity and assess the fitness for surgery

\section{Details of procedure \\ Informed consent}

medications: All patients received

prophylactic antibiotic treatment 60 minutes before surgical incision.

\section{Position:}

-of the patient: supine, shoulders are supported on a sand bag to extend the neck, head is supported on a ring to prevent side displacement.

-of the table: head tilted up to 15 degree to decrease venous engorgement.

Adverse effects: increase the incidence of air embolism if a large vein is injured.

Of the surgeon: To be on the side opposite the lobe to be operated on

Skin preparation: Operative field was sterilized by povidone-iodine from the mandible to the nipple.

Anesthesia: General anesthesia was used in all patients of studied sample.

Incision: -Collar(kochers) incision was done $2 \mathrm{~cm}$ above the suprasternal notch, extending to the posterior end of the sterno-mastoid muscles.

\section{Procedure}

Incision of the skin and the superficial fascia with platysma muscle.

Elevation of the flaps of the skin and platysma superiorly to the thyroid cartilage and Inferiorly to suprasternal notch.

Flaps are kept in position by thyroid retractors or two silk sutures fixed to the towel.

Division of the investing layer, and the pretracheal fascia in the midline.

Exposure: Delivery of the thyroid lobe by plunt (finger) dissection from the deep surface of pre-tracheal fascia and strap muscles.

De vascularization of the thyroid lobe by ligation of:

1-Middle thyroid vein first because it is the shortest with attention to the non-recurrent 
laryngeal nerve not to be injured during the ligation.

2-Superior thyroid artery and vein as close as possible to the upper lobe of the gland to avoid injury of the external laryngeal nerve.

3-Inferior thyroid artery away from the lower pole of the gland to avoid injury of the recurrent laryngeal nerve, ligated in continuity to avoid fall of the proximal stump in the chest.

4-Inferior thyroid veins at the lower pole of the gland.

5-Division of the isthmus between two Kocher's forceps.

Exploration of the contralateral lobe, and if fine nodularity is found total thyroidectomy was done if indicated.

\section{Hemostasis.}

\section{Suction drain.}

Closure: continuous suture to avoid hemorrhage, closure of the pre-tracheal fascia at the midline, pre-tracheal muscles if cut,

\section{RESULTS:}

Patient's age of the studied sample showed that 14 patients $(56 \%)$ their age was less than 30 years, 7 patients $(28 \%)$ their age between $30-40$ years, 3 patients $(12 \%)$ their age between $40-50$ subcutaneous tissue including the platysma, and skin .

Check the vocal cords during the extubation by direct laryngoscope

Post operative care: Resected thyroid specimen was sent for histo-pathological examination, patient was in semi-sitting position, care of the respiration, close follow up of the drain and removal after 24 hour if no active bleeding, post operative antibiotic and analgesic, discharge the patient and Follow up of the wound for infection, flap necrosis, and seroma till complete healing and removal of the stitches.

Post-operative data: Results of histopathological examination of the post-operative thyroid specimen resected were analyzed.

Statistical Analysis:Data were collected and coded to facilitate data manipulation and double entered into Microsoft Access and data analysis was performed using Statistical Package of Social Science (SPSS) software version 18 in windows 7

Table (5): Distribution of studied sample according to patient's age

\begin{tabular}{|l|l|l|}
\hline Age & No. & $\%$ \\
\hline$<30$ ys & 14 & $56 \%$ \\
\hline $30-40$ ys & 7 & $28 \%$ \\
\hline $40-50$ ys & 3 & $12 \%$ \\
\hline$>50$ ys & 1 & $4 \%$ \\
\hline Total & 25 & $100 \%$ \\
\hline Min.-Max. & $20-55 y s$ & \\
\hline Mean \pm S.D & $33.00 \pm 9.5 y s$ & \\
\hline
\end{tabular}


Pre-operative FNAC was intended to be done routinely for all patients, and its results showed that 5 patients (20\%) were colloid adenoma, 12 patients (48\%) were follicular lesion for surgical resection and histopathological examination, 7 patients (28\%) were papillary adenoma, 1 patient (4\%) was papillary thyroid carcinoma underwent total thyroidectomy with lymph node dissection.(Table (11))

Table(11): Distribution of studied sample according to pre-operative FNAC results.

\begin{tabular}{|l|c|c|}
\hline Pre-operative FNAC & Number & $\%$ \\
\hline Colloid adenoma & $\mathbf{5}$ & $\mathbf{2 0 \%}$ \\
\hline Follicular lesion & $\mathbf{1 2}$ & $\mathbf{4 8 \%}$ \\
\hline Papillary adenoma & 7 & $\mathbf{2 8 \%}$ \\
\hline Papillary carcinoma & 1 & $4 \%$ \\
\hline Total & $\mathbf{2 5}$ & $\mathbf{1 0 0 \%}$ \\
\hline
\end{tabular}

The patients were divided according to the size of the nodule (in maximum diameter) in postoperative histopathology report into three groups:

Group (A) the size of the nodule was less than $2 \mathrm{~cm}$ including 2 patients $(8 \%)$, there post-operative histopathology results were follicular adenoma

Group (B) the size of the nodule range between $2-4 \mathrm{~cm}$ including 20 patients ( $80 \%$ ), there post-operative histopathology results were as follow: 4 patients were colloid adenoma, 7 patients were papillary adenoma, 6 patients were follicular adenoma, 2 patients were follicular carcinoma, and 1 patient was papillary carcinoma.

Group (C) the size of the nodule is more than $4 \mathrm{~cm}$ including 3 patients $(12 \%)$, there post-operative histopathology results were as follow: one patient was follicular adenoma, one patient was colloid adenoma, and one patient was follicular carcinoma.

In general, patients nodule size ranged between $1.5-5 \mathrm{~cm}$ with mean \pm S.D. $3.5 \pm 1.5$ cm.(Table 13)

The patients were divided according to the size of the nodule by US (in maximum diameter) in to the same categorization done for post-operative size of the nodules: group (A) size less than $2 \mathrm{~cm}$, group (B) size $2-4 \mathrm{~cm}$, and group (c) size more than $4 \mathrm{~cm}$, In comparison between size of the nodule in preoperative US and post-operative histopathology reports it is the same with minimal difference $\pm 1-2 \mathrm{~mm}$ which didn't affect our categorization of the nodules according to its size.(Table 14)

Table(14):Distribution of the studied sample according to the nodule size in preoperative US compared to nodule size in postoperative histopathology reports.

\begin{tabular}{|l|l|}
\hline Nodule Size in each group & Size by US
\end{tabular}




\begin{tabular}{|l|l|l|}
\hline & & $\begin{array}{l}\text { Size in post-operative } \\
\text { pathology }\end{array}$ \\
\hline Group (A):size $<2 \mathrm{~cm}$ & $2(8 \%)$ & $2(8 \%)$ \\
\hline Group (B):size 2-4 cm & $20(80 \%)$ & $20(80 \%)$ \\
\hline Group (C):size $>4 \mathrm{~cm}$ & $\mathbf{3 ( 1 2 \% )}$ & $\mathbf{3 ( 1 2 \% )}$ \\
\hline Total & $25(100 \%)$ & $\mathbf{2 5}(100 \%)$ \\
\hline Min.-Max. & $1.5 \mathrm{~cm}-5 \mathrm{~cm}$ & \\
\hline Mean \pm S.D & $3.5 \mathrm{~cm} \pm 1.5 \mathrm{~cm}$ & \\
\hline
\end{tabular}

Patient's post-operative histopathology of the examined specimen showed that 5 patients (20\%) were colloid adenoma, 9 patients (36\%) were follicular adenoma, 5 patients $(20 \%)$ were papillary adenoma, 2 patients $(8 \%)$ were papillary adenoma with cystic degeneration, 3 patients $(12 \%)$ were follicular carcinoma and 1 patient (4\%) was papillary thyroid carcinoma (PTC).(Table (15))

Table(15): Distribution of studied sample according to patient's post-operative histopathology.

\begin{tabular}{|l|l|l|}
\hline Post-operative Histopathology & No & $\%$ \\
\hline Colloid adenoma & 5 & $20 \%$ \\
\hline Follicular adenoma & 9 & $36 \%$ \\
\hline Papillary adenoma & 5 & $20 \%$ \\
\hline $\begin{array}{l}\text { Papillary adenoma \&cystic } \\
\text { degeneration }\end{array}$ & 2 & $\mathbf{8 \%}$ \\
\hline Follicular carcinoma & 3 & $12 \%$ \\
\hline papillary carcinoma & 1 & $\mathbf{4 \%}$ \\
\hline Total & 25 & \\
\hline
\end{tabular}

The patients were divided according to the post-operative histopathology results into two groups:
Benin group (1) including 21 patients (84\%) 5 patients of them were colloid adenoma, 9 patients were follicular adenoma, and 7 patients were papillary adenoma. 
Malignant group (2): including 4 patients, 3 patients of them were follicular carcinoma, and 1 patient was papillary carcinoma.

Regarding the correlation between the size of the nodule and the incidence of malignancy the results of the studied sample showed the following:

Group A in which the nodule size was less than $2 \mathrm{~cm}$ : included 2 patients and both were benign.

Table(16): Distribution of studied sample according to patient's post-operative histopathology in correlation with the incidence of malignancy.

\begin{tabular}{|l|l|c|}
\hline Groups of nodule size & $\begin{array}{c}\text { Benign } \\
\text { No. }(\%)\end{array}$ & $\begin{array}{c}\text { Malignant } \\
\text { No. }(\%)\end{array}$ \\
\hline Group A:<2cm & 2 patients(100\%) & Zero(0\%) \\
\hline Group B:2-4cm & $\mathbf{1 7}$ patients $(\mathbf{8 5} \%)$ & $\mathbf{3}$ patients(15\%) \\
\hline Group C: $>$ 4cm & 2 patient $(67 \%)$ & 1 patients $(33 \%)$ \\
\hline
\end{tabular}

Group B in which the nodule size range between $2-4 \mathrm{~cm}$ : included 20 patients, 17 patients of them were benign, and 3 patients were malignant.

Group $\mathrm{C}$ in which the nodule size was more than $4 \mathrm{~cm}$ : included 3 patients, one of them was colloid adenoma, one was follicular adenoma, and one was follicular carcinoma. Table (16)

\section{DISCUSSION}

Many studies have been published on the risk of malignancy in thyroid nodules; these studies show that the risk of malignancy is low, approximately $5 \%$, unless the patient has an underlying risk factor, such as a history of external neck irradiation. ${ }^{15}$ Some studies shown that thyroid nodule size can be considered as an independent indication to predict the risk of malignancy in people with thyroid nodules. But other studies did not support these data and even reported against their results. Furthermore, diagnostic accuracy of FNAB in large thyroid nodules is still controversial. ${ }^{16}$ In our study patient's age ranged between $20-55$ years with mean \pm S.D. $33 \pm 9.5$ years. Patient's sex of the studied sample showed that patients $(100 \%)$ were females, 0 patients $(0 \%)$ is male, as the study was intended to be done on female patient. In Godazandeh et al the mean ages of 
In the present study pre-operative FNAC was intended to be done routinely for all patients, and its results showed that $(20 \%)$ of patients were colloid adenoma, (48\%) of patients were follicular lesion for surgical resection and histo-pathological examination, $(28 \%)$ of patients were papillary adenoma, (4\%) of patients were papillary thyroid carcinoma who underwent total thyroidectomy with lymph node dissection.

Shere SK et al study divided the patients according to the result of pre-operative FNAC into four groups: inadequate, benign, malignant, and suspicious. In patients with inadequate smears FNAC was repeated guided with ultrasound then the results were benign smears, and suspicious smears. As FNAC cannot distinguish between follicular adenoma and follicular carcinoma. FNAC diagnosis of this study was supported by postoperative histo-pathological report. Final diagnosis in this study was based on the post-operative histo-pathological confirmation ${ }^{18}$

In the present study, the patients were divided according to the size of the nodule (in maximum diameter) in post-operative histopathology reports into three groups: Group (A) the size of the nodule was less than $2 \mathrm{~cm}$ including (8\%) of the patients; there post-operative histopathology results were follicular adenoma, Group (B) the size of the nodule range between $2-4 \mathrm{~cm}$ including $(80 \%)$ of the patients, there post-operative histopathology results were as follow: $16 \%$ were colloid adenoma, $28 \%$ were papillary adenoma, 24\% were follicular adenoma, $8 \%$ were follicular carcinoma, and $4 \%$ were papillary carcinoma, Group (C) the size of the nodule is more than $4 \mathrm{~cm}$ including (12\%) of the patients; there post-operative histopathology results were as follow: $4 \%$ were follicular adenoma, $4 \%$ were colloid adenoma, and $4 \%$ were follicular carcinoma. In general, the patient's nodule size ranged between $1.5-5 \mathrm{~cm}$ with mean \pm S.D. $3.5 \pm 1.5$.

Patient's post-operative histopathology of the examined specimen showed that $(20 \%)$ of patients were colloid adenoma, (36\%) of patients were follicular adenoma, $(28 \%)$ of patients were papillary adenoma, (12\%) of patients were follicular carcinoma and $(4 \%)$ of patients were papillary thyroid carcinoma (PTC).

Regarding the correlation between the size of the nodule and the incidence of malignancy, the results of the studied sample showed the following:

Group A in which the nodule size was less than $2 \mathrm{~cm}$ : included $8 \%$ of patients and all were benign (100\%), and incidence of malignancy in this group was zero $(0 \%)$.

Group B in which the nodule size ranged between $2-4 \mathrm{~cm}$ : included ( $80 \%)$ of patients, $85 \%$ of them were benign, and incidence of malignancy in this group was (15\%).

Group $\mathrm{C}$ in which the nodule size was more than $4 \mathrm{~cm}$ : included $12 \%$ of patients, $(67 \%)$ of them were benign, and incidence of malignancy in this group was (33\%).

Kamran SC et al Study reported that the increasing thyroid nodule size had an influence on cancer risk in a nonlinear fashion, and there was no increase in the risk beyond the $2 \mathrm{~cm}$ threshold. $^{3}$

Berker D et al. reported no significant difference between $1 \mathrm{~cm}$ nodules and $4 \mathrm{~cm}$ in malignancy risk. ${ }^{19}$ However McCoy et al. have shown higher prevalence of thyroid carcinoma in nodule size $\geq 4 \mathrm{~cm}$. ${ }^{16}$

Conversely, Rausei et al and McHenry et al reported higher prevalence of thyroid carcinoma in smaller nodules. $^{20,21}$

Three studies demonstrated a higher risk of malignancy in nodules $\geq 4 \mathrm{~cm}$ compared to $<4$ $\mathrm{cm}$ : Bestepe $\mathrm{N}$ et al reported a risk of malignancy $24 \%$ in nodules $\geq 4 \mathrm{~cm}$ versus $12 \%$ in nodules $<4 \mathrm{~cm}$ in 571 patients ${ }^{22}$, While Kuru B et al reported a risk of $58.2 \%$ in nodules $\geq 4 \mathrm{~cm}$ versus $37.3 \%$ in nodules $<4 \mathrm{~cm}$ in 159 patients ${ }^{23}$, and Kamran SC et al reported a risk of $15 \%$ in nodules $\geq 4 \mathrm{~cm}$ versus $12.3 \%$ in nodules $<4 \mathrm{~cm}$ in 4955 patients. ${ }^{3}$ While our study reported a risk of 
$15 \%$ in nodule size $<4 \mathrm{~cm}$ versus $33 \%$ in nodule size $\geq 4 \mathrm{~cm}$.

In our study, we observed that the incidence of malignancy in nodule size $<4 \mathrm{~cm}$ is $15 \%$ versus $33 \%$ in nodule size $\geq 4 \mathrm{~cm}$, while

\section{CONCLUSION}

Management of thyroid nodules is based on clinical context, US criteria, and fine needle aspiration biopsy cytology. These contradictory results show that the size of the nodule is not reliable at predicting malignancy and should not be applied for medical decision

\section{REFRENCES}

[1] MrtesonJD,WoolnerLB,BennetWA.G roos and microscopic findings in clinically normal thyroid gland.Jclin Endocrinal metab1955;15(10):127080.(pubmed:13263417).

[2] singerPA.Evaluationand management of the solitary thyroid nodule.OtolaryngolClin North Am 1996;29(4):57791.(PubMed:8844731).

[3] Papini E, Guglielmi R, Bianchini A, Crescenzi A, Taccogna S, Nardi F, et al. Risk of malignancy in nonpalpable thyroid nodules:predictive value of ultrasound and color-Doppler features. J ClinEndocrinolMetab 2002;87(5):1941-

6.(PupMed:11994321).

[4] Nam-Goog IS, Kim HY,Gong G, Lee HK, Hong SJ,KimWB,et al. Ultrasonography-guided fine needle aspiration of thyroid incidentaloma: correlation with pathological findings. ClinEndocrinol(oxf)2004;60(1):218.(PupMed:14678283).

[5] Kamran SC, Marqusee E, Kim MI, FratesMC, RiterJ,PetersH,et al. Thyroid nodule size and prediction of cancer.

ClinEndocrinolMetab2013;98:56470. the risk of malignancy in each group is not increasing in a linear manner, there was no statistically significant difference between malignant and benign nodules in size, and nodule size can't be considered as a dependent risk factor of malignancy in STN.

making, the nodule size should be precisely documented for the purpose of follow-up, as increase in the size of a nodule, especially when significant, may be a predictor for malignancy and an indication for repeating biopsy.

[6] barroetje,wang $h$, shiina $n$, guptapk, livolsiva, baloch $\mathrm{ZW}$. Isfine-needle aspiration (FNA) of multiple thyroid nodules justified? EndocrPathol 2006;17(1):61-[PubMed:16760581].

[7] Ferrone S, Marincola FM, Lossof HLA class 1 antigens by melanoma cells:moleculermechanisms,functiona lsignificance and clinical revalence.Immunol Today 1995;16(10):487-94 .[PubMed:7576053]

[8] HegedusL.Clinicalpractice.The thyroid nodule. $\mathrm{N}$ Engl $\mathrm{J}$ Med 2004;351(17)1764-

71.[PubMed:15496625]

[9] Cooper DS, Doherty GM, Haugen BR, et al. Revised American Thyroid Association management guidelines for patients with thyroid nodules and differentiated cancer.Tyroid.2009;19(11):11671213.

[10] Ezzat S, Sarti DA, Cain DR, Braunstein GD. Thyroid incidentalomas. Prevalence by palpation. and ultrasonography. Arch Intern Med 1994;154(16):1838-40. [PubMed: 8053752]

[11] Gharib H, Goellner JR. Fine-needle aspiration biopsy of the thyroid: an 
appraisal.

$\mathrm{Am}$

Intern

Med.1993;118(4):282-289.

[12] Yassa L, Cibas ES, Benson CB, et al. Long-term assessment of amultidisciplinary approach to thyroid nodule diagnostic evaluation.cancer.2007;111(6):508516.

[13] Raparia K, Min SK, Mody DR, Anton $\mathrm{R}$, AmrikachiM.Clinical outcomes for suspicious category in thyroid fineneedle biobsy:Patient's sex and nodule size are possiblepredictors of malignancy. Arch Pathol Lab Med.2009;133(5):787-790

[14] Mendelson AA, Tamilia M, Rivera J, et al. Predictors of malignancy in preoperative nondiagnostic biopsies of the thyroid. J Otolarrngol Head Neck Surg.2009;38(3):395-400. 15.Wienke JR, Chong WK, Fielding JR, Zou KH \& Mittelstaedt CA. Sonographic features of benign thyroid nodules. Journal of Ultrasound Medicine 200322 10271031.

[15] McCoy KL, Jabbour N, Ogilvie JB, Ohori NP, Carty SE, Yim JH. The incidence of cancer and rate of falsenegative cytology in thyroid nodules greater than or equal to $4 \mathrm{~cm}$ in size. Surgery. 2007; 142(6):837-44. e3

[16] Godazandeh, G., Kashi, Z., Zargarnataj, S., Fazli, M., Ebadi, R., \& Kerdabadi, E. H. (2016). Evaluation the Relationship Between Thyroid Nodule Size with Malignancy and Accuracy of Fine Needle Aspiration Biopsy (FNAB). Acta informatica medica: AIM: journal of the Society for Medical
Informatics of Bosnia \&Herzegovina: casopis Drustva za medicinsku informatiku BiH,24(5),347-350.

[17] Shere SK, Kulkarni AS, Phulgirkar PP et al (2013): Correlation of fine needle aspiration cytology with histopathology in diagnosis of thyroid lesions. In: journal of evolution of medical and dental science, vol, 12.issue, 26.july, 2013.pages; 48264831

[18] Berker D, Aydin Y, Ustun I, Gul K, Tutuncu Y, Isik S, et al. The value of fine-needle aspiration biopsy in subcentimeter thyroid nodules. Thyroid. 2008;18(6):603-8

[19] Rausei S, Dionigi G, Frattini F, Castano P, Leotta A, Rovera F, et al. Nodule size and fine-needle aspiration biopsy: diagnostic challenges for thyroid malignancy. The American Journal of Surgery. 2011;201(4):525-30

[20] McHenry CR, Huh ES, Machekano $\mathrm{RN}$. Is nodule size an independent predictor of thyroid malignancy? Surgery. 2008;144(6):1062-9

[21] Bestepe N, Ozdemir D, Tam AA, Dellal FD, Kilicarslan A, Parlak O, et al. Malignancy risk and false-negative rate of fine needle aspiration cytology in thyroid nodules $\geq 4.0 \mathrm{~cm}$. Surgery. 2016

[22] Kuru B, Gulcelik NE, Gulcelik MA, Dincer $H$. Predictive index for carcinoma of thyroid nodules and its integration with fine-needle aspiration cytology. Head Neck. 2009;31:85666. 